\title{
Clinical interpretation of "health and the human spirit for occupation".
}

Janice P. Burke

Thomas Jefferson University

Follow this and additional works at: https://jdc.jefferson.edu/otfp

Part of the Occupational Therapy Commons

Let us know how access to this document benefits you

\section{Recommended Citation}

Burke, Janice P., "Clinical interpretation of "health and the human spirit for occupation"." (1998).

Department of Occupational Therapy Faculty Papers. Paper 45.

https://jdc.jefferson.edu/otfp/45

This Article is brought to you for free and open access by the Jefferson Digital Commons. The Jefferson Digital Commons is a service of Thomas Jefferson University's Center for Teaching and Learning (CTL). The Commons is a showcase for Jefferson books and journals, peer-reviewed scholarly publications, unique historical collections from the University archives, and teaching tools. The Jefferson Digital Commons allows researchers and interested readers anywhere in the world to learn about and keep up to date with Jefferson scholarship. This article has been accepted for inclusion in Department of Occupational Therapy Faculty Papers by an authorized administrator of the Jefferson Digital Commons. For more information, please contact: JeffersonDigitalCommons@jefferson.edu. 


\title{
Clinical Interpretation of "Health and the Human Spirit for Occupation"
}

\author{
Janice Posatery Burke
}

Key Words: chronic disease $\bullet$ health $\bullet$ human activities and occupations

Janice Posatery Burke, PhD, OTR/L, FAOTA, is Assistant Professor and Director of Graduate Programs, Deparrment of Occupational Therapy, Thomas Jefferson University, 130 South 9th Street, Suite 810, Philadelphia, Pennsylvania 19107.

This article was accepted for publication March 6, 1998.

The American Journal of Occupational Therapy 
outcomes of occupational therapy intervention that are not always readily recognizable or measurable. It appears that we are closer to being able to articulate the kinds of behaviors that we search out in our patients as well as the kinds of changes that are made in treatment. These include many of the behaviors that often go unnoticed in the recovery effort (being able to problem solve simple daily living tasks, feeling pleasure from activity, approaching a task in an organized manner). Each of us has experienced a patient's final days in treatment when what is remembered and recognized most about the intervention are the obvious physical differences (moving, talking), with far less attention given to changes in abilities such as overcoming boredom or learning to act on the environment. We are now bringing to a conscious level the untold complexities of occupational therapy.

If, as Yerxa (1998) reports, persons experience a sense that they have lost their place in the world with the onset of a disability, then we as occupational therapists need to spend treatment time setting out the kinds of experiences and opportunities that will influence a relocation of the self, including rekindling interests and satisfaction in everyday doing. Many of us do this very thing in our work with patients but have lacked the vocabulary to be able to talk about those treatment results as they occur in contemporary practice.

The immediate application of Yerxass (1998) work to clinical practice is obvious in the kind of case questions we ask. Why is it that one person with mild or even moderate deficits can be much more disabled than another person with more severe or widespread disabilities? More specifically, why is it that Mr. L. is able to reinvent an occupational identity for himself in spite of his severe paralysis secondary to multiple sclerosis, whereas $\mathrm{Mr}$. T. with resolving Guillain-Barré syndrome is unable to construct even a beginning view of himself when asked what he wants to be able to do when he goes home? Our understanding of these types of questions may become clearer if we begin to explore which patients possess the capacities for adaptedness as described by Pörn (1993). If we assess "adequacy of one's repertoire,... appropriateness of one's environment" (Yerxa, 1998, p. 414), and realistic qualities of the person's goals, might we have the information we need to develop and enact successful occupational therapy intervention plans for the many different kinds of patient problems we encounter? Our ability to tie these adaptedness behaviors to health and recovery will be among the most crucial tasks to be accomplished during the recovery phase of treatment. Indeed, we can begin to understand our unique contribution by looking more closely at occupation and its role in the recovery process. What kind of progress does the patient make when occu- pation is interwoven into the treatment plan? Do we see differences in treatment progress when interests and skills are assessed and treatment plans are constructed to reflect them?

As we begin to test these ideas and develop treatment that is based on them, we will no longer find ourselves indistinguishable from our colleagues on the treatment team. What we do now has come to look too much like the work of others (it takes place in the occupational therapy/physical therapy gym, documentation is concerned with the skills and functions associated with activities of daily living, e.g., dressing, bathing). Moving toward occupation-centered practice requires use of materials and environments that closely mimic the kinds of occupations that people engage in daily (in home settings, in simulated work spaces, at a kitchen table, at a desk, at a computer). Treatment interactions require us to identify and stimulate interest and the willingness to become engaged (making choices, recognizing boredom and cues for action).

Clinical research grounded in occupation can support our occupational therapy contribution to understanding the reinstatement of health. For example, in a recently funded federal research project, a colleague and I have hypothesized that outcomes of care for persons with traumatic brain injury may not depend solely on the availability of certain kinds of service (outpatient day rehabilitation, work coach, vocational education training) but on what occupation-related factors are being addressed and encouraged during interventions. For example, does this person live close to and use public transportation, thus providing a way to get where he or she wishes to go? How has the person's family members reacted to the disability? To what degree is the person able to continue in family roles and routines, and what has been the impact of the person's disability on the family members' perceptions of their loved one's ability to reach their stated goals?

When occupation is put into the center of our work in program development, we take an important role in directing and overseeing patient programs and individual patient care plans. This is the case in community-based settings. In a meeting recently, I sat across from an occupational therapy colleague who reported on the progress of a needs assessment she had been contracted to provide. She noted that the longer she was with the project, the more time she seemed to be giving to it. When asked what she thought that meant, she shared that it was not because the work was difficult but rather that the more the agency personnel learned about what occupational therapists could do, the more populations and areas of programming they brought to the table to be included in the needs assessment. Similarly, we are seeing that when we begin to introduce occupational therapy services into settings such as homeless shelters or a centers for mothers 
with drug addiction, we find that clients, other professionals, and administrators are sufficiently impressed with the results of our interventions to secure funds to continue our occupation-based services.

Managed care's concerns for patient satisfaction may again create need for our expertise in matching activity to the person. Administrators of managed care plans are beginning to recognize that people want a say in what they believe is a satisfactory choice of care. They may soon permit persons to choose a setting for care within their system by allowing the participant to visit several settings to determine which is the best choice. In this scenario, occupation-driven programs will be important because they display the range and types of activities that persons are able to be involved in during the treatment process. The fit berween what is offered and the types of activities participants see as most like their own preferences for acrivity and interaction will influence their selections. For example, they may consider the following: Will my husband fit best in a setting that stacks cones to increase wrist and hand function or in a setting that allows him to choose among a home repairs module; a computer module; and a dart board, chess, and gaming module?

\section{Therapist-to-Therapist Talk}

Talk between therapists is an important means by which knowledge of health and the human spirit spread. When therapists begin ralking to one another in the language of occupation, they are drawn into a dialog that will change their work. Therapists rely on one another to test their ideas about their patients, to share their frustrations and stuck points, and to boast of their breakthroughs and successes. Therapist talk is a powerful source for learning and sharing information in our culture of occupational therapy. It is where we pass the knowledge and wisdom of patient care from one generation of therapists to the next. When therapists adopt a language that allows them to talk about occupation behaviors (i.e., meaningful variety, meaningful redundancy), then we will stand a greater chance of bringing occupation-related concepts to our conscious daily practice. Once we think and speak to one another in this way, we are poised on the threshold of talking across disciplines to colleagues who are also concerned about resilience and potential in patients with chronic disabilities.

\section{Converting Ideas Into Clinically Oriented Research Actions}

Yerxa's (1998) look into the future and the contributions that an understanding of occupation can make to health and well-being confirms many of the hunches that occupational therapists have about their contribution to understanding and intervening with populations that will be newly identified as "at risk." I am ever mindful of this concept each time I visit my 80 -year-old mother. In spite of a rather tarnished health history replete with hypertension and such, my mother has grown to be a spry, funloving, and energetic octogenarian. Of course, she has benefited from good preventive health monitoring and aggressive intervention over the course of her life. Even more striking is the way she conducts her daily life. This 80-year-old woman keeps herself busy around her house in a wide range of physically, socially, and psychologically rewarding activities. To name but a few of her regular occupations, she participates in an informal social gathering that takes place in the mornings after daily mass, helps her elderly neighbor, cooks for her nearby family, sews, organizes her home, works at her desk managing her personal finances, follows the lives of her children and grandchildren, looks for and locates various objects that her family members call her for ("Grandma do you have any old skirts, I'm in a play," "Grandma I need a red tie"), and listens to her daughters' endless joys and sorrows. Clearly, my mother's strongly developed interests (in sewing, cooking and baking, keeping a home) provide her with "the economy of human happiness by fulfilling the need for autonomy, leading to both adaptation and creativity" (Yerxa, 1998, p. 413).

What is most interesting is to contrast my mother's activity patterns and sense of purpose with her sister, 5 years her junior. My aunt has been single her whole life. Although emotionally close to her three sisters and their families, she lived alone most of her adult life, working outside of her home in a typical 5-day, 40-hour workweek. Her weekends and days off were spent catching up on sleep, relaxing, and hanging around. When retirement came to my aunt, it brought a sense of freedom, sleeping as late as she wanted, reading as much as she wished. Indeed, my aunt adored her early retirement days. But as time has moved on, she has come to find less and less enjoyment in her free time. With little or no skill in structuring or occupying her time, finding social contacts, connecting her goals to a broader set, or deriving a sense of identity in activity outside of work, my aunt now finds her days to be long and empty. Constantly calling on my morher to help her fill her time, she tries to lure my mother out for lunch, coffee, and just plain contact. My aunt often says that she "hates" her house, and although she likes to imagine herself involved in volunteer work outside of her home, cannot manage to put her dream into action. Beset by some minimal to moderate physical limitations and a lack of skill in defining and acting on interests, my aunt has not been able to move beyond her pattern of unrewarding daily occupations.

I know from my conversations with therapists and students that there is a tremendous amount of recogni- 
tion of and interest in the kinds of clinical and research concerns that turn around "occupation" such as I just illustrated in this clinical interpretation. That Yerxa (1998) has connected many of our own musings with ideas and concepts from contemporary literature proves the perfect start point for therapists to test and talk about what they find as they practice occupational therapy.

\section{References}

Pörn, I. (1993). Health and adaptedness. Theoretical Medicine, 14, 295-303.

Yerxa, E. J. (1998). Healch and the human spiric for occupation. American Joumal of Occupational Therapy, 52, 412-418.

\section{SUBSCRIBE TO OT BIBSYS}

A Biblographic Guide to OT Literature

\section{To Access: Go to AOTA's homepage http://www.aota.org and click on OT BibSys.}

OT BibSys is a bibliographic database covering the literature of occupational therapy and related subject areas.

- More current information than other indexing services

- More than 25,000 references listed

- Each listing includes source of material and abstract if available-not full text

- Search by subject, author, or title

- Includes literature published outside the United States

- References to OT literature begin in the early 1900 s

- Includes lists of articles from non-OT journals written by OTs or of definite interest to OTs

- Formerly on The Reliable Source

Subscription price for institutions is $\$ 500 /$ year; individual AOTA members pay $\$ 75 /$ year, or 1 month use for $\$ 15 ;$ individual nonmembers pay $\$ 200 /$ year, or 1 month use for $\$ 25$.

To subscribe: Send check payable to The American Occupational Therapy Association, Inc., or prepaid purchase order to AOTA Subscriptions, PO Box 31220, Bethesda, MD 20824-1220

For more information call:

1-800-SAY-AOTA (AOTA members) or 301-652-2682 (nonmembers), extension 2742

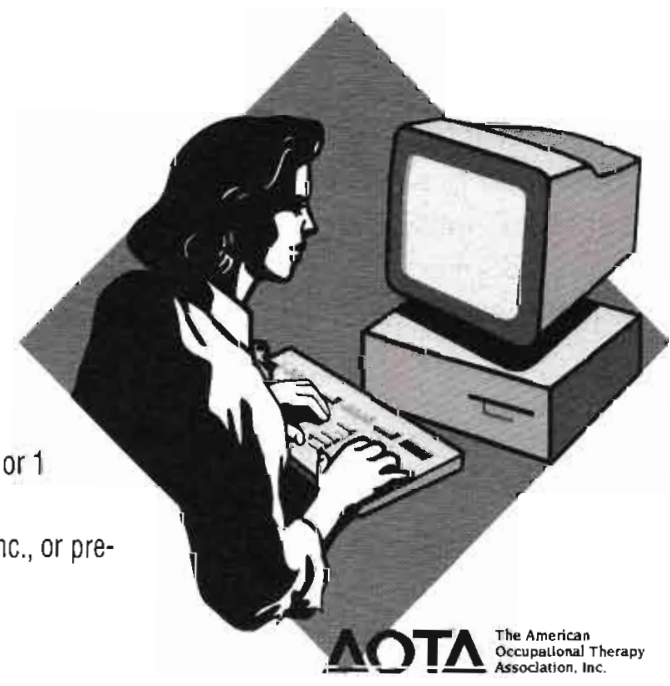

